\title{
Lembrar Virilio, pintor das antiformas
}

\author{
Remembering Virilio, Painter of Antipatterns
}

\section{Tiago Quiroga}

Pós-doutor em antropologia pela Freie Universität Berlin; doutor em ciências da comunicação pela Escola de Comunicações e Artes da Universidade de São Paulo (ECA-USP); mestre em comunicação e cultura pela Escola de Comunicação da Universidade Federal do Rio de Janeiro (ECO-UFRJ). Atualmente é professor adjunto da Faculdade de Comunicação (FAC), Universidade de Brasília (UnB), vinculado ao Programa de Pós-Graduação em Comunicação na linha de pesquisa de Teorias e Tecnologias da Comunicação.

\section{Kaique Agostineti}

Doutorando do PPGCom da Faculdade de Comunicação da Universidade de Brasília. Mestre em comunicação pelo PPGCom da Faculdade de Informação e Comunicação da Universidade Federal de Goiás. Bacharel em Comunicação Social com habilitação em Jornalismo pela Faculdade de Informação e Comunicação da Universidade Federal de Goiás. Discente do curso de Filosofia da Universidade Federal de Goiás.

\section{RESUMO}

Em 10 de setembro de 2018, morria, aos 86 anos, Paul Virilio, vítima de ataque cardíaco, na cidade litorânea de La Rochelle, onde morara desde sua aposentadoria, em 1999, pela École Speciale d'Architecture (ESA) de Paris. A fatalidade e a crescente importância de suas ideias em diversos campos do saber, entre eles o da comunicação, orientam a realização do presente ensaio. Seguindo apontamentos biográficos e marcos conceituais, procura-se rememorar sua obra, sinalizando problemas e hipóteses que, decisivos, nos ajudam a compreender fenômenos contemporâneos. Tal itinerário encontra-se organizado em cinco chaves de leitura: Virilio, filho da guerra total; Pintor das antiformas; Um arquiteto prático da inclinação; 0 anarcocristão; 0 crítico da arte tecnológica. 


\section{ABSTRACT}

On September 10, 2018, at the age of 86, Paul Virilio died of a heart attack in the coastal city of La Rochelle, where he had lived since retiring in 1999 from the École Speciale d'Architecture (ESA) in Paris. His death and the growing importance of his ideas in several fields of knowledge, among them communication studies, provide the basis for this essay. Following biographical notes and conceptual milestones, we seek to remember his work, pointing out problems and hypotheses which help us understand contemporary phenomena. This itinerary is organized under five key categories: Virilio: son of total war; Painter of antipatterns; A practical inclination architect; The anarcho christian; A critic of technological art. KEYWORDS: Paul Virilio; Biographical essay; Life; Work.

\section{Introdução}

Há pouco mais de um ano, Paul Virilio era vítima de um ataque cardíaco na cidade litorânea de La Rochelle, onde residia desde sua aposentadoria, em 1999. A fatalidade e a crescente importância de suas ideias têm justificado novos mergulhos em sua obra, de modo a dela extrair problemas, hipóteses e conceitos que nos auxiliem a pensar a atualidade. Já na apresentação da edição brasileira de Pure War (1984), primeiro livro do ensaísta e pensador francês ${ }^{1}$ em nosso país, o sociólogo da tecnologia Laymert Garcia dos Santos afirmava ser urgente e necessária a divulgação do pensamento do autor no Brasil. Santos observava que a obra de Virilio era então praticamente desconhecida por aqui: "desconhecida e no entanto vital para todos nós" (Santos, 1984, p. 7). Em sua opinião, o ensaísta teria ouvido como poucos a questão que ressoava em todas as latitudes e categorias sociais no final do século XX, ocasião em que muitos se perguntavam onde iríamos parar. Ao contrário daqueles que, diante dos presságios de um futuro sombrio para a humanidade, preferiam esquecer o problema, o autor propunha outro movimento:

\footnotetext{
Arquiteto, urbanista, homem dos espaços, Paul Virilio ouviu a exclamação que sua boca articulava. Ouviu e, em vez de recalcar, acolheu-a. E viu o diabo na rua, no meio do redemoinho... E descobriu que o onde é indissociável do movimento que nos leva e de sua velocidade - o movimento da máquina-de-guerra mundial. Mais ainda: que esse movimento consome e desintegra o espaço, os lugares; e que, no limite, o movimento absoluto, pura velocidade, chega a lugar nenhum. Porque não há mais lugar, porque, em sua aceleração, o movimento esgotou o espaço do planeta (SANTOS, 1984, p. 8).
}

\footnotetext{
1 Pure war consiste em uma entrevista realizada por Sylvere Lotringer com Paul Virilio.
} 
Para Santos, Virilio observou que não era mais possível responder a essa questão, pois o movimento se convertia num imperativo, a velocidade se tornava um fim em si mesmo, a implosão do mundo destruía os locais de chegada, o espaço do planeta diminuía. Santos afirma que o ensaísta francês se engajou como poucos no questionamento da máquina-de-guerra planetária e que ele teria descoberto, horrorizado, que o mundo estava sob um permanente estado de emergência, o que evidenciava a urgência de uma análise crítica da relação entre a velocidade, a tecnociência e o poder militar. Virilio (1994, 1996, 1999) considerava, já no século XX, que o poder militar alcançava dimensões que extrapolavam os contornos comumente atribuídos a seu domínio. Em seu primeiro livro, Bunker Archéologie (1994), ele apresenta o tema central da primeira fase de seu pensamento, explicitado no subtítulo da edição brasileira de Pure War: a militarização do cotidiano. Na ocasião, Virilio se indagava acerca de um processo mais amplo e transversal: a constante aceleração da vida humana e suas várias implosões - "implosão psíquica, política, social, econômica, sexual, implosão de linguagem" (Santos, 1984, p. 7).

Ora, desde sua primeira publicação no Brasil, a obra e o pensamento de Virilio vêm ganhando cada vez mais relevância, principalmente em decorrência do tempo em que vivemos, marcado pelas vertigens da aceleração, pela inundação tecnológica e midiática, e, no cenário brasileiro, pela preocupante volta do militarismo desavergonhado. Por meio então do progressivo entrelaçamento de itinerários biográficos e conceitos centrais, o presente artigo procura rememorar sua obra, situando chaves de leitura acerca de fenômenos em pleno funcionamento hoje, em especial aqueles que envolvem a aceleração como base do vínculo entre tecnologias e poder na reorganização dos territórios. De modo mais específico, o ensaio procura mostrar como a vida e a obra do autor levaram à sua formação como crítico do militarismo e das utopias tecnológicas que, segundo ele, tanto marcam os discursos correntes na atualidade (Armitage, Virilio, 2000). Em síntese, procura-se pensar com Virilio não apenas a crescente militarização do cotidiano, mas em que medida o binômio finança-tecnologia acaba por ratificar a lógica da guerra na base da sociedade contemporânea.

Antes de tudo, gostaríamos de realizar alguns esclarecimentos. Como um primeiro passo, admitimos que não apresentamos aqui um trabalho definitivo: não objetivamos narrar minuciosamente a vida de Paul Virilio; tampouco queremos interpretá-la na chave de um biografismo autoritário. Buscamos apenas reunir fragmentos dispersos em várias entrevistas e 
obras $^{2}$ que servirão de ponto de partida para novas análises. Concordamos com Derian (1998) quando ele afirma que nenhuma biografia pode ou poderá explicar Virilio. Em segundo lugar, é preciso de dizer que o recurso ao itinerário biográfico teve como objetivo apenas introduzir o leitor ao pensamento do ensaísta francês por meio da explicitação de certas passagens, episódios e encontros de sua vida, e, nesse sentido, não intentamos encerrar as possibilidades interpretativas que surgem durante a leitura de suas obras. Trata-se de um pano de fundo para seu pensamento, principalmente no que diz respeito às diversas relações entre a velocidade, as tecnologias e a militarização.

Por fim, cabe destacar a posição privilegiada que os meios de comunicação e informação ocupam no pensamento de Paul Virilio. Encontramos diversas análises referentes a eles ao longo de sua obra. Para o autor, o desenvolvimento acelerado dos meios de informação e comunicação produziria transformações em nossas condições epistemológicas e políticas. Segundo Virilio, seria preciso problematizar os desenvolvimentos das tecnologias de informação e comunicação, oferecendo uma perspectiva que explicitasse as tendências ocultas sob o véu das tecnoutopias informativas civilizacionais. A rigor, ao perseguir o problema da militarização do cotidiano e ancorá-lo no progresso da velocidade - centro de sua cosmologia conceitual -, o ensaísta francês encontra um tema que lhe permite transitar por diferentes domínios do saber. Assim, ele propõe um novo modo de olhar para vários campos, como arquitetura, urbanismo, política, geopolítica, sociologia, comunicação etc. No entender de Virilio, torna-se premente pensar o entrelaçamento dos objetos pertinentes a essas áreas e a militarização avançada de nossas vidas no final do século XX, início do XXI. Se esse processo se apoia na aceleração promovida pelo desenvolvimento das tecnologias de transporte e comunicação, podemos dizer que o ensaísta nos convoca a pensar as relações desses campos com a alta velocidade tecnológica, indiscernível da própria vida em nossos contextos atuais. Nas palavras de James (2007, p. 1): “o trabalho de Virilio nos mostra como e por que a tecnologia foi, e continuará a ser, fundamental para a formação da experiência humana e o desenvolvimento histórico". ${ }^{3}$

Assim, partimos da questão “Quem foi Virilio?" para compreender como seu percurso leva à formação de um olhar crítico em relação aos temas da velocidade, do poder militar

\footnotetext{
2 Retiramos os fragmentos das obras de Virilio (1994, 1999, 2005), Armitage $(2000,2001)$, Derian (1998) e Redhead (2004).

${ }^{3}$ Nessa e nas demais citações em idioma estrangeiro, a tradução é nossa.
} 
generalizado e das tecnologias de comunicação e informação. Essa questão delineia cinco atos de leitura que serão explorados nas seguintes seções: Um filho da guerra total, que narra sua infância e adolescência vividas durante a Segunda Guerra Mundial; 0 pintor das antiformas, que descreve seu trabalho como artesão de vitrais e conta suas experiências com desenho e pintura; 0 arquiteto prático da inclinação, que relata a participação de Virilio no grupo Architecture Principe, bem como o início de sua vida acadêmica na École Speciale d'Architecture de Paris; 0 anarcocristão, que narra sua conversão ao cristianismo, experiência fundamental para a formulação de suas concepções políticas; e, por fim, 0 crítico da arte tecnológica, que analisa sua formação como fenomenólogo e o direcionamento de sua obra para a crítica da velocidade, da tecnologia e do militarismo em oposição ao que ele descreve como fundamentalismo tecnológico. Ao longo de cada seção, buscaremos explicitar, ainda que brevemente, conceitos e entendimentos presentes na obra do autor e que traçam uma relação entre essas vivências e os objetos de seu pensamento.

\section{Virilio, filho da guerra total}

Filho de pai italiano e mãe francesa, Paul Virilio nasceu em Paris em 4 de janeiro de 1932, em uma França prestes a ser invadida pelo exército nazista e transformada em campo de batalha durante a Segunda Guerra Mundial. Com a proximidade do conflito, sua família se mudou para Nantes em 1939. Porém, a fuga não adiantaria: a cidade localizada no noroeste francês logo seria dominada e integrada à área de ocupação alemã entre 1940 e 1944. Assim, Virilio passou parte de sua infância e início de sua adolescência em meio à zona de guerra, observando in loco os acontecimentos do conflito, conforme lembra em entrevista a Armitage: “testemunhei o drama da guerra total e, através dele, vivi as milhões de mortes, as cidades arrasadas ao chão, tudo isso" (Armitage, Virilio, 2000, p. 26). 0 autor narra algumas vivências do período no prefácio de sua segunda obra, Essai sur l'insécurité du territoire. Entre elas, podemos observar a passagem em que relata a experiência da destruição da Rue du Calvaire, em Nantes, em 1943:

Recordo o mês de setembro de 1943. Havia ido, nessa mesma manhã, à Rue du Calvaire, a essa rua fervilhante, àquelas lojas cheias de objetos, de brinquedos... ao anoitecer, tudo havia desaparecido, sutilizado pelo acontecimento, o acontecimento sobre o acontecimento, a guerra sobre a paz da vida cotidiana; a grande rua de uma cidade a centenas de quilômetros de todas as frentes de batalha - ativa por seus usos mais diversos, pelas trocas e as cumplicidades, pelo céu sobre as calçadas e os reflexos nas vitrinas - havia se convertido em Verdun. Intempestivamente, tudo havia se movido: desapareceram os imóveis, as perspectivas, os alinhamentos das fachadas 
se volatizaram... o céu, a transparência e a sombra das ruínas em meio ao amontoamento de pedregulhos e cascalho (VIRILIO, 1999, p. 10-11).

Nessa passagem de sua adolescência, Paul Virilio narra as consequências da chegada do céu à história, isto é, a conquista do espaço aéreo com a utilização efetiva de aviões de combate durante o conflito mundial. Esse outro cenário se tornou um palco decisivo onde ocorriam as perseguições entre caças, produzindo o que ele chamou de céu primitivo da Segunda Guerra Mundial. Sobre essa experiência vivida em Nantes, o ensaísta explica que, justamente em 1943, foram abolidas inúmeras resistências morais dos dois lados do conflito. A frota aérea aliada pôde assim colocar em prática, no continente europeu, a estratégia de zoneamento da destruição, que consistia em soltar bombas sobre o território nazista sem fazer distinção entre os espaços civil e militar. A conquista do céu, com a utilização frequente do avião, veículoarmamento de guerra, possibilitou a implementação dessa tática, produzindo o fenômeno da exposição total da superfície do planeta pela implosão do espaço, que resultava das altas velocidades da máquina atmosférica. Essa contração do espaço terrestre leva o ensaísta a afirmar que tudo se movia com a chegada do céu na história no século XX (Virilio, 1999). Por causa dessa mobilidade, uma cidade situada a centenas de quilômetros do front de batalha pôde ser convertida em um alvo destinado ao desaparecimento intempestivo, transformandose rapidamente em ruínas. Paul Virilio nos apresenta, por meio de sua memória, a configuração de uma nova realidade: o deslocamento geral produzido pela conquista aérea faria girar completamente a vida cotidiana, presa em sua horizontalidade ou na bidimensionalidade do território. Todas as cidades se tornariam portos de um novo litoral, o litoral vertical. Isto é, todas se transformariam em um espaço de intercâmbio entre ao menos dois elementos: a terra e o ar.

O autor relata diversas ocasiões em que tais intercâmbios teriam ocorrido. Ele evoca as pessoas abandonando seus postos e afazeres ao ouvir o rugido das esquadras voadoras; também se lembra de que colecionava as relíquias do combate que caíam do céu, como panfletos, cápsulas e dejetos de equipamentos abatidos. Outra lembrança bastante viva é a dos alertas noturnos que levavam todos os citadinos para os abrigos subterrâneos. Virilio recorda que os sons das sirenes ecoavam pela cidade e despertavam o medo geral, forçando um compartilhamento afetivo e aflitivo entre os nazistas e seus dominados. Ele explica:

Por certo, a situação dos citadinos franceses era surpreendente: o inimigo coabitava aqui embaixo, na pacífica cotidianidade, mesmo quando, às vezes, seus excessos interrompiam a vida ordinária; ali estava ele, ao nosso lado, 
banalizado pelos anos de ocupação, enquanto os Aliados, os nossos, derramavam bombas sobre a cidade (VIRILIO, 1999, p. 11).

Há nesse compartilhamento um importante elemento da guerra total: o controle do medo civil. Virilio lembra que os nazistas produziram fotomontagens propagandísticas, direcionadas aos cidadãos franceses, mostrando as ruínas da cidade de Paris após um hipotético ataque aliado. 0 autor também relata que, naquele tempo, os dominadores incentivavam os dominados a cavar um buraco em suas casas para proteger suas famílias das ameaças aéreas de seus libertadores. Essas peças de propaganda nazista visavam causar nos dominados mais temor do que esperança de libertação. Elas se referem ao que Paul Virilio posteriormente chamou de administração do medo, cujo objetivo era engajar os civis franceses na tarefa da proteção do Lebensraum, por meio da espionagem e da delação de pessoas e movimentos suspeitos. Desse modo, o regime nazista produzia um tipo de gangsterismo oficial: ele oferecia proteção em troca de informações acerca do território e do corpo social (Virilio, 1994, 1996, 1999).

Além desses relatos, Virilio também nos conta uma de suas experiências vividas após o término do conflito, a descoberta do mar. Essa memória é narrada no prefácio de Bunker Archéologie, texto que inicia afirmando: “durante a minha juventude, uma obra no litoral europeu proibiu o acesso a ele; [os nazistas] estavam construindo uma muralha, e eu não descobriria o oceano, no estuário do Loire, antes do verão de 1945" (Virilio, 1994, p. 9).

A proibição de acesso ao litoral francês foi consequência do planejamento do espaço rapidamente conquistado pelo exército alemão logo nos primeiros anos do conflito. Uma vez alcançados os limites continentais, o regime nazista precisou elaborar uma estratégia defensiva ante o ataque iminente dos Aliados. A solução arquitetada por Hitler e pelo corpo de militares e engenheiros do Terceiro Reich foi a construção da fortaleza continental, a Festung Europa. A obra que impedia o acesso de Virilio ao litoral era a Atlantikwall, uma das principais infraestruturas desse projeto. Ela consistia em uma linha de defesa formada por cerca de 15 mil bunkers e estações de apoio, que se estendia da fronteira litorânea norte, entre a Espanha e a França, à Dinamarca e à Noruega. O ensaísta assinala que todo o litoral tinha sido reorganizado em torno dessas construções. Assim, a beira-mar se tornou uma região proibida. 
Por causa de tais circunstância, Paul Virilio precisou esperar até o verão de 1945 para conhecer o mar. Ele considerou esse encontro uma experiência duplamente preciosa, pois conquistar o acesso à praia significava também o fim da guerra. Essa significância contribuiu para que ele não esquecesse nenhum ponto dessa descoberta. Então recorda que a sensação mais clara a emergir daquele encontro foi a da ausência: a cidade litorânea estava parcialmente destruída e inteiramente despovoada; as ruas, vazias de carros; a praia, deserta; o horizonte oceânico fora totalmente limpo. Virilio narra:

\begin{abstract}
Era meio-dia, a verticalidade luminosa e a horizontalidade líquida compunham um clima surpreendente. Avançando em meio às casas com as janelas escancaradas, estava ansioso para superar os obstáculos que me separavam do horizonte do Atlântico; na verdade, estava ansioso para pisar em minha primeira praia. Ao me aproximar da Ocean Boulevard, o nível da água começou a subir entre os pinheiros e as moradias; o oceano foi ficando cada vez maior, ocupando cada vez mais espaço no meu campo de visão. Finalmente, ao cruzar a avenida paralela à costa, a linha de terra parecia ter mergulhado na ressaca, deixando tudo liso, sem ondas e com pouco barulho. Mais um elemento estava ali diante de mim: a hidrosfera (VIRILIO, 1994, p. 10).
\end{abstract}

Tanto a passagem da descoberta do mar quanto a da destruição da Rue du Calvaire têm grande importância no pensamento posterior do autor. A partir delas, Paul Virilio desenvolve conceitos relevantes em suas obras, como hidrosfera, a administração do medo, litoral vertical etc. Mais importante, neste ponto, é notar que essas memórias da infância e adolescência ajudaram Virilio a formular uma relação quase sanguínea entre sua vida e a Segunda Guerra Mundial. Por isso, o ensaísta se autointitula uma criança da Blitzkrieg ou um filho da guerra total (Armitage; Virilio, 2000). A metáfora do parentesco fica ainda mais clara quando o autor afirma:

\begin{abstract}
A Segunda Guerra Mundial foi a minha mãe e o meu pai. A extremidade das situações vividas me instruiu: não se trata de complacentes violências [...], mas de uma visão de mundo, inalterável. A Segunda Guerra Mundial é um reservatório de sentidos indispensável para a segunda paz, a nossa paz (VIRILIO, 1999, p. 15).
\end{abstract}

Nessa declaração, podemos observar que há mais do que a intimidade com o horror do combate. Virilio argumenta que a experiência da guerra o instruiu porque as situações testemunhadas o levaram a criar uma visão de mundo que o ajudou a compreender não somente o conflito, mas o tempo que se iniciava após o término das batalhas. Desse modo, ele considera que a Segunda Guerra significou mais do que um trauma: ela se tornou um reservatório de conhecimentos que o auxiliaram na tarefa de compreender o presente. Por essa razão, o autor afirma que a guerra foi sua verdadeira universidade (Armitage, Virilio, 2000) - 
as experiências vividas como soldado na Argélia, bem como na militância antinuclear francesa, complementam o quadro de sua formação empírica. Desde então, essas memórias retornam como ponto de entrada para as diversas análises do autor. De acordo com ele, a militarização do cotidiano torna a vida um prolongamento daquele tipo que era possível levar no campo de batalha. 0 regime da Paz Total que, segundo seu entendimento, impera após o conflito mundial, com a dissuasão nuclear e a inércia polar, é tão somente a guerra continuada por outros meios (Virilio, 1999). Portanto, o autor extrai de sua vivência a ideia de um estado de sítio global, propiciado e administrado pelo desenvolvimento da velocidade das tecnologias de guerra, transporte, comunicação e informação.

\section{Pintor das antiformas}

Após o término da guerra, Virilio passou a frequentar a École des Métiers d'Art, em Paris, antes de se tornar artesão de vitrais e trabalhar na restauração de igrejas, como SaintPaul-de-Vence e Varangeville-sur-Mer, ao lado de artistas renomados como Georges Braque e Henri Matisse (Armitage, Virilio, 2000; Redhead, 2004).

0 autor revela que, no final da década de 1940, para conseguir dinheiro, trabalhou com pintura de pôsteres de filmes, chegando a pintar o cartaz do filme Sansão e Dalila, do diretor estadunidense Cecil B. DeMille, lançado em 1949. Ao relembrar seu interesse na produção dessas peças naquela época, Virilio afirma que os trabalhos de Paul Colin, Cappiello e Cassandre o atraíam porque ele percebia uma relação entre eles e a pintura de murais. Outro importante evento que contribuiu para esse interesse foi mais uma experiência de guerra: Virilio afirma ter visto o famoso Affiche Rouge no tempo da ocupação alemã em Nantes (Carlut, Joubert, Virilio, 2001).

Se esse resumo é suficiente para relatar a incursão profissional de Virilio no campo das artes, ele é incapaz de revelar o verdadeiro interesse do autor por desenho e pintura ao longo de sua vida. Ele narra esse empenho em L'Horizon Négatiff, obra publicada em 1984, na qual afirma que, desde sua infância, suas inclinações tenderam mais para o mundo das aparências, das figuras representativas ou geométricas, que para os números da matemática ou da história (2005).

Sem remeter a datas, Virilio recorda que seus dois primeiros desenhos foram os de uma mulher caminhando pela Rue Saint Jacques, em Nantes, e de uma ponte sobre o rio Loire ambas cenas de sua juventude na zona de guerra. Em sua opinião, essas figuras aparentemente 
banais se mostrariam posteriormente significativas, pois se alinhavam com os interesses gerais de seu pensamento. Por um lado, a ponte era um tipo de arca, um dos arquétipos arquitetônicos trabalhados por Virilio em Bunker Archéologie. Por outro, para ele, o assunto do primeiro desenho era menos a mulher que sua marcha, o que o levava a comparar tal desenho àqueles estudos sobre os movimentos dos seres humanos e animais das cronofotografias referências recorrentes em seus livros.

Segundo o autor, essa atração pela representação do movimento nas imagens fixas tinha relação com seu interesse por desenhos animados, principalmente as metamorfoses produzidas por Émile Cohl. O ensaísta também relaciona esse primeiro assunto ao entusiasmo que sentia pelas pinturas orientais, que carregavam o desejo de representar aquilo que não poderia ser representado. Em sua opinião, isso significava uma descoberta: "as formas, as coisas, emitem e recebem, elas emitem as suas realidades sensíveis e o que elas passaram, e recebem e devolvem a totalidade do sentido de seu meio e de seus entornos, e isso ao longo do curso de suas existências" (Virilio, 2005, p. 27). Desde então, Virilio compreendeu que sua busca era pela aparência silenciosa das coisas, o que levava à necessidade de pintar o pictórico como um questionamento a nosso modo de ver as figuras.

Assim, o autor descobriu seu território: a fenomenologia das figuras, da representação como questionamento, a busca da aparência silenciosa dos objetos. Isso o colocava em posição diferente das tendências da pintura de sua época, cada vez mais abstrata. Para ele, a abstração não poderia existir, pois tudo representa uma figura. A ideia de algo que não possui forma, daquilo que é vazio, só poderia ter sido produzida na cultura por uma civilização de predadores, como a civilização ocidental. E, pior, a primazia da arte abstrata teria levado ao que ele chamou, posteriormente, de procedimento de silenciamento no campo da arte. Isto é, uma autocensura do campo artístico na busca de coibir a arte representativa. De seu ponto de vista, a oposição entre abstração e figuração era uma armadilha comum no Ocidente; era a encenação no círculo da arte de um processo de exclusão da diferença e, consequentemente, de redução da pluralidade das formas expressivas.

Contra o reducionismo, Virilio (2005) narra uma experiência que realizou enquanto morava em Paris. Ele revela que, naquele tempo, passou a se interessar por objetos sem valor, começando a traçar algumas naturezas-mortas. Espalhava utensílios de cozinha no chão de seu apartamento, sem qualquer arranjo sensível ou composição. Segundo ele, esse era um estudo ascético, e seus visitantes não entendiam a riqueza daquilo que procurava. 0 autor conta que prosseguia durante horas nessa atividade aparentemente sem sentido para os outros: a busca 
da aparência silenciosa das coisas, das formas como se escondem agora, mas que vão determinar a novidade do amanhã. Ele relata que, ao olhar demoradamente tais objetos, algo lhe acontecia:

\begin{abstract}
De repente, na minha frente, novos objetos apareceram, figuras bizarras serrilhadas ou entalhadas; uma coleção completa de articulações se tornou subitamente visível, e esses objetos de observação não eram mais banais, de nenhum modo, ou insignificantes. Pelo contrário, eram extremamente diversos, estavam em todos os lugares, ao longo do espaço; o mundo todo estava repleto dessas formas, aninhadas nos buracos das formas mais desprezadas; era como uma vegetação desconhecida que se proliferava ao meu redor; objetos inúteis ganhavam a aparência de objetos momentâneos de extrema complexidade, a posição das coisas desencadeando novas formas exóticas, formas que, embora fossem claramente visíveis, nos escapavam, habituados como estávamos com a geometria trivial. Enquanto percebemos perfeitamente círculos, esferas, cubos ou cantos, nossa percepção dos intervalos, dos interstícios entre as coisas, entre pessoas, é muito menos acurada (VIRILIO, 2005, p. 29).
\end{abstract}

Os objetos momentâneos eram os intervalos ou os interstícios das coisas, as formas irregulares que surgiam na relação entre figura e fundo, os utensílios e o chão do apartamento. Para ele, os objetos intersticiais são figuras passageiras; escapam rapidamente de nossa visão, de modo que nunca parecem importantes. Se as coisas em primeiro plano podem ser chamadas de formas, os intervalos são as antiformas. Enquanto os objetos apresentam uma simetria típica do mundo industrial, as antiformas sofrem metamorfoses, variando de acordo com nosso movimento. $\mathrm{O}$ autor compara essa experiência a uma jornada num espaço constituído por uma geografia intersticial.

Virilio afirma ter-se tornado um caçador das antiformas, desejando expulsá-las de seus esconderijos e inventariá-las. Essa descoberta aparentemente banal possui extrema relevância para a compreensão do trabalho teórico do autor. Segundo James (2007), podemos entender o pensamento de Virilio como uma aplicação dessa visão intersticial desenvolvida durante suas experiências com desenho e pintura. 0 comentador sugere que essa vivência lhe permitiu questionar a política da percepção, os modos de ver predominantes na formação ocidental. Virilio tentaria inverter essa perspectiva e observar as realidades ignoradas, escondidas no espaço intervalar das formas presentes na experiência contemporânea. Ou seja, Virilio questionou os modos de ver herdados por ele, buscando sempre um encontro diferente com a realidade. Tais experiências fundamentaram um modo de perscrutar o mundo; por meio delas, Virilio passou a indagar as antiformas presentes nos processos políticos, econômicos, sociais e culturais que constituem a realidade. 


\section{0 arquiteto prático da inclinação}

Paul Virilio já estava próximo da arquitetura quando trabalhou como artesão de vitrais na restauração de igrejas. No entanto, sua entrada definitiva nesse campo se deu a partir do seu interesse pela arquitetura militar das estruturas da Atlantikwall, no litoral norte da França, na década de 1950. Ele narra esse episódio da descoberta dos bunkers no prefácio de Bunker Archéologie. Passando as férias de 1958 em uma praia em Saint-Guénolé, ao fitar o horizonte marítimo ininterrupto, uma sensação o trouxe de volta a seu corpo; ele percebeu que se escorava em uma massa de concreto inclinada. Essa estrutura fazia parte de um bunker, uma construção que, até aquele momento, só havia atraído seu interesse como mero vestígio da Segunda Guerra Mundial. Virilio decide explorar essas estruturas, observa suas características, redescobre esse objeto. Seu interesse o leva a uma pesquisa de cerca de oito anos sobre as estruturas da Festung Europa (Virilio, 1994). Como um arqueólogo, ele cataloga as edificações... Assim, compreende que elas possuíam alguns significados profundos, justificando então a origem do livro Bunker Archéologie, publicado em 1975.

Enquanto ainda realizava a pesquisa no litoral europeu, Virilio conheceu o arquiteto parisiense Claude Parent (1923-2016) e então decidiu comprar um apartamento projetado por ele em Paris, em 1963. Segundo Parent (apud Redhead, 2004), o ensaísta francês ainda trabalhava como artesão de vitrais, mas tinha um verdadeiro instinto para a arquitetura. De modo fortuito, os dois começaram uma parceria que os levou, no mesmo ano, à formação do grupo de estudos Architecture Principe.

Além de Virilio e Parent, também participavam desse grupo o pintor Michel Cerrade e o escultor Morice Lipse. Tinham como principal objetivo "investigar e promover um novo tipo de ordem urbana e arquitetural" (Redhead, 2004, p. 22). Na prática arquitetônica, Virilio e Parent idealizaram e construíram a Igreja de Santa Bernadete, em Nevers (França), em 1966, e o Centro de Pesquisas Espaciais Thomson-Houston, em Villacoubly (França), concluído em 1969.

Nosso autor considerava a primeira dessas obras a mais marcante. A edificação ficou conhecida como igreja-bunker, pois os idealizadores realizaram nela um cruzamento da religião com a guerra, resultando numa forma arquitetônica incomum para edifícios sacros. Sobre tal obra, Virilio diz que desejava cristianizar o bunker como uma prefiguração do abrigo atômico que remontava ao arquétipo da cripta. "Em Lourdes, a Virgem Maria apareceu a Santa Bernadete numa gruta. Agora, tanto a gruta quanto o bunker são criptas, lugares escondidos, como na palavra inglesa, cryptic [enigmático]" (Armitage, Virilio, 2000, p. 32). Esse cruzamento 
entre as temáticas religiosa e bélica, segundo ele, também foi motivado por suas viagens pela Alemanha, durante a pesquisa de Bunker Archéologie. Em Dusseldorf, ele afirma ter visto abrigos antiaéreos que haviam sido convertidos em igrejas protestantes e católicas; ali, lhe teria ocorrido essa clara relação entre tais estruturas militares e as igrejas enquanto lugares de adoração, proteção e salvação.

Contudo, podemos dizer que a principal contribuição do Architecture Principe foi o desenvolvimento de uma teoria arquitetural crítica aos padrões de pensamento construtivo dominantes naquela época. 0 grupo abriu espaço para a expressão dessa visada, ao lançar uma revista com título homônimo, publicando nove edições entre os meses de fevereiro e dezembro de 1966. Nelas, Virilio e Parent desenvolveram a ideia de função oblíqua, a arquitetura em plano inclinado.

Para eles, a intensa verticalização das cidades no período pós-guerra era uma espécie de apagamento da memória; a utilização militar do avião tornava os prédios alvos bastante fáceis de atingir - o 11 de setembro de 2011 nos mostrou essa realidade. Segundo Virilio (1999), a ortogonalidade adotada na reconstrução do continente expressava uma submissão dos países europeus aos ditames da ordem bipolar mundial. A arquitetura servia assim aos interesses militares das duas potências: ao mesmo tempo em que expressava esse sentido macropolítico, ela também carregava significados micropolíticos:

\footnotetext{
Naquele tempo, torres estavam sendo construídas em todas as partes, nas margens do Sena e em outros lugares. A torre era o tipo de arquitetura mais exaltado. Nossa oposição a elas era absoluta. A verticalidade era um absurdo, pois não permitia a comunicação. Ela apenas causou concentração, empilhamento. A verticalidade é um gueto. Quando as pessoas falam sobre guetos raciais, nós respondemos: "sim, esses são guetos horizontais" (LIMON; VIRILIO, 2001, p. 54).
}

Outro ponto de crítica ao conceito de função oblíqua reside na problematização da relação da arquitetura com o corpo. Virilio entende que a horizontalidade e a verticalidade são ordens arquitetônicas que pouco desenvolvem nossa corporeidade, principalmente quando preenchidas com tecnologias destinadas ao conforto, como o elevador. Os propositores entendiam que a função oblíqua possibilitava resgatar uma associação perceptiva inevitável entre o corpo e a superfície da Terra. Como afirma James (2007, p. 11), "esse ambiente de superfícies inclinadas iria, por assim dizer, afirmar uma relação entre o movimento do corpo e sua localização física". Assim, esse outro princípio arquitetônico colocava em primeiro plano nossa realidade corporal inserida no espaço e no tempo. Nesse sentido, James entende que, ao mesmo tempo em que recusa alguns aspectos dos desenvolvimentos tecnológicos 
contemporâneos, Virilio afirma as possibilidades de nossos corpos, das várias maneiras possíveis de habitarmos os espaços. Grande parte das críticas do autor às tecnologias, incluindo as tecnologias de comunicação e informação, encontra seus alvos nessas tentativas generalizadas de promover a recusa de nossa condição corporal.

O grupo Architecture Principe durou apenas cinco anos, entre 1963 e 1968. Seu término foi motivado por divergências políticas entre Virilio e Parent. Nosso autor explica: "esse era um típico 'grupo jovem'. E ele se rompeu com os 'eventos' de maio de 1968. Eu estava muito envolvido nesses eventos, enquanto Claude Parent era contra a coisa toda. Então nós seguimos rumos diferentes. Eu fui para a esquerda e ele para a direita" (Armitage, Virilio, 2000, p. 33). Sobre os movimentos de maio de 1968, o autor conta que, quando os estudantes tomaram a universidade, ele fez um cartaz que reeditava uma escritura gravada na entrada da Sorbonne: “a imaginação assume o poder". Por seu envolvimento e apoio aos estudantes, ele precisou fugir de Paris e se esconder na Bretanha para não ser preso pelas forças de Charles de Gaulle (Limon, Virilio, 2001).

Após esses acontecimentos, em 1969, Paul Virilio foi convidado a lecionar na École Speciale d'Architecture (ESA) de Paris, apesar de não possuir qualquer instrução formal em arquitetura e urbanismo. Ele afirma que os estudantes dessa escola tinham ouvido falar dele nessa época, e, por isso, o convidaram a lecionar lá, onde permaneceu como professor desde então, tendo se tornado diretor em 1975. Em 1987, por suas contribuições à área, Virilio recebeu o Grand Prix National de la Critique Architecturale da França. 0 autor também foi promovido a presidente da ESA em 1990 e, em 1999, recebeu o título de professor emérito da escola, se aposentando no mesmo ano.

\section{0 anarcocristão}

Outra importante experiência de Paul Virilio foi sua conversão ao catolicismo em 1950. A esse respeito, ele observa:

quando eu era jovem, eu me converti ao cristianismo. Eu me converti quando tinha 18 anos, como um adulto. A guerra tinha acabado recentemente, e eu tinha visto coisas terríveis, e essa foi uma das razões que fizeram com que eu me convertesse ao cristianismo. Mas você deve saber que eu me converti na companhia dos "padresoperários' [prêtre-ouvrier]. Na França, os padres-operários eram aqueles que assumiam um trabalho industrial e iam viver entre os trabalhadores das fábricas. Não exibiam sua cruz pastoral; escolhi me converter com eles porque eu queria algo real, não um show religioso com alguém em uma fantasia (ARMITAGE; VIRILIO, 2000, p. 29). 
Segundo o autor, essa conversão ao cristianismo no movimento dos padres-operários influenciou decisivamente sua visão de mundo, pois o aproximou de um tipo de pensamento de esquerda que não se alinhava aos comunismos stalinistas ou maoístas atuantes no século XX. 0 autor brinca, afirmando que esse afastamento pode ser tomado como um tipo de revolta contra seu pai, que era comunista (Armitage, Virilio, 2000). Na verdade, ele diz rejeitar essas visões políticas, pois sempre lhe pareceram fenômenos totalitários. Por outro lado, ele também recusa fortemente aquele tipo de culto pregado por Bush, Clinton ou Blair. Como afirma Readhead (2004), Paul Virilio era extremamente crítico em relação ao cristianismo militarizado das potências do Ocidente.

Embora o ensaísta afirme a Armitage (2000) que a religião não foi a principal influência de seu trabalho - razão pela qual ele evita comparações com autores cristãos como Chardin e Ellul -, para James (2007), é praticamente impossível entender a posição política de Virilio sem recorrer ao movimento e ao pensamento personalistas de Emmanuel Mounier na década de 1930. James explica que Mounier criou uma doutrina política que denunciava o liberalismo, o individualismo, o capitalismo industrial, o totalitarismo ascendente e o ordenamento tecnológico do Estado moderno. Contra isso, propagava a ideia de uma comunidade organizada em torno de valores humanos e relações pessoais. Para o comentador, tais críticas e propostas estão na base das ideias de Virilio sobre a atualidade. James acredita que o autor teria entrado em contato com a doutrina personalista no movimento dos padres-operários e nos cursos de fenomenologia de Maurice Merleau-Ponty.

A vida religiosa de Virilio ainda o levou, na década de 1950, a trabalhar com o abade Pierre em defesa da habitação popular. Ele sempre se engajou nessa causa. Junto ao fundador do movimento Emaús, Virilio também atuou no Alto Comitê para Habitação dos Destituídos, criado pelo presidente François Mitterand e continuado durante a administração de Jacques Chirac, na década de 1980. 0 autor continuou a lutar por essa agenda após deixar o comitê, em parceira com projetos beneficentes da Igreja Católica (Armitage, Virilio, 2000).

Por esses atravessamentos entre o catolicismo não tradicional e seu pensamento político de esquerda, crítico ao Estado e ao capitalismo modernos, Virilio se definia como um anarcocristão. Essa posição pode ser observada na leitura que faz da vida de Jesus Cristo em Essai sur l'insécurité du territoire. Para o autor, Jesus Cristo morreu sob uma única acusação: inimigo do Estado, pois se recusou a aderir à estadolatria romana (Virilio, 1999). Essa interpretação o leva à denúncia do que ele chamou de idealidade morfológica do Estado do Ocidente, uma forma que se localiza no fundo, nos interstícios da história, agindo sorrateira e 
decisivamente em nossas vidas e na organização de nossa formação política. Assim, a conversão ao cristianismo o leva à crítica do militarismo imbricado e estimulado pelo Estado Ocidental.

\section{0 crítico da arte tecnológica}

Ao longo de sua carreira intelectual, Virilio foi frequentemente associado ao pósmodernismo e a outros renomados pensadores franceses contemporâneos, como Deleuze, Guattari, Derrida, Foucault e Baudrillard. Na entrevista a Armitage (2000), o autor busca desfazer essas associações comuns, afirmando que considera o pós-modernismo uma catástrofe em termos arquitetônicos e pouco interessante no campo do pensamento, ao mesmo tempo entendendo que Deleuze, Guattari, Derrida e Foucault - os três primeiros seus amigos pessoais - se diferenciavam dele por possuírem instrução formal e porque eram influenciados por Friedrich Nietzsche, a quem Virilio admirava mais pela escrita do que pela filosofia. Além disso, julgava que Baudrillard - que também era seu amigo - tinha abraçado um niilismo com o qual não concordava. Por isso, o ensaísta afirma que as aproximações entre seu pensamento e o desses autores eram mais um tipo de paralelismo do que de convergência.

Se quisermos encontrar as verdadeiras fontes intelectuais do pensamento de Paul Virilio, devemos recorrer aos cursos ministrados por Maurice Merleau-Ponty na Sorbonne no final da década de 1950. Nessa época, ele tem contato com a fenomenologia da percepção do filósofo francês e com os trabalhos de Edmund Husserl. Outro importante campo de interesse do autor foi a Gestalt. Porém, apesar dessas referências, Virilio revela a Armitage (2000) que sempre se considerou um pensador marginal, não se encaixando perfeitamente em nenhuma corrente consolidada. Isso porque ele considera que a principal influência para seu trabalho não foi um autor específico, mas a Segunda Guerra Mundial.

Podemos aceitar também a hipótese desenvolvida por James (2007), para quem Virilio se inspirou nas fenomenologias de Husserl e Merleau-Ponty, mas também prosseguiu os entendimentos de Benjamin acerca da reprodutibilidade técnica. James (2007, p. 5) resume sua proposta afirmando que "Virilio partilha com Husserl a ideia de que a experiência moderna é formada pela visão tecnocientífica do mundo e, como Husserl, ele busca desvelar, redescobrir e analisar um reino de percepção sensorial mais imediato, que precede as abstrações do conhecimento científico". 0 comentador entende, todavia, que Husserl dificilmente aceitaria a aproximação que Virilio faz da fenomenologia com as ideias de Benjamin, isto é, "a ideia de que 
os fundamentos da percepção podem ser modelados ou 'treinados' pela tecnologia, uma vez que ele busca demonstrar suas constância universal e consistências lógicas" (James, 2007, p. 5). Por isso, James considera que Virilio parte dessa via fenomenológica para desenvolver uma visada original em que a tecnologia - e a aceleração da velocidade por ela proporcionada adquire um papel central na configuração de nossas percepções e na organização do espaço social, político e cultural da modernidade.

Esse caminho de questionamentos originais acerca da circularidade das tecnologias em nossas vidas leva o autor à criação de uma obra de mais de 40 livros, dos quais nove foram traduzidos e publicados no Brasil. De modo geral, podemos aceitar a classificação proposta por Armitage (2000) acerca da periodização dessa obra: na década de 1970, Virilio tinha como foco central a militarização do espaço urbano com a desterritorialização da ordem moderna e o desenvolvimento da cronopolítica; nos anos 1980, ele se preocupou com temáticas relacionadas à percepção e à tecnologia; na década de 1990, o autor passou a pensar os efeitos das tecnologias cibernéticas e de informação e comunicação na sociedade hipermoderna. Podemos acrescentar ainda outra fase: nos anos 2000, Virilio procurou se defender dos ataques provenientes de críticos em relação ao tom pessimista de suas obras, elaborando a teoria do acidente. Esta última fase começou a ser desenvolvida no final da década de 1990, mas a principal obra que a representa, L'accident originel, só foi publicada em 2005. Virilio explica sua teoria da seguinte maneira:

\footnotetext{
toda vez que uma tecnologia é inventada, pegue a navegação, por exemplo, um acidente é inventado junto com ela, nesse caso, o naufrágio, que é exatamente contemporâneo à invenção do navio. A invenção da ferrovia significa, necessariamente, a invenção do desastre ferroviário. A invenção do avião trouxe o desastre aéreo em seu despertar. [...] Esse é um ponto fundamental, porque as pessoas tendem a focar no veículo, a invenção propriamente, mas não no acidente, que é a sua consequência. Como crítico da arte tecnológica, eu sempre tento enfatizar ambos, a invenção e o acidente (ARMITAGE, VIRILIO, 2000, p. 40).
}

Virilio se defende da acusação de apocalíptico das tecnologias ao se colocar como "crítico da arte tecnológica", isto é, alguém que deseja apontar suas positividades e negatividades. Assim, conforme dizem Armitage (2000) e Redhead (2004), o ensaísta tem consciência do tom aparentemente pessimista de seus ensaios. Contudo, ele entende que precisa se posicionar desse modo contra a campanha publicitária que acompanha as invenções tecnológicas, a qual nos faz esquecer os acidentes, promovendo um fundamentalismo tecnológico. Sobre essa posição, Virilio conclui argumentando que muitos já estão acostumados com a ideia de um crítico de arte, mas poucos aceitam a posição de crítico da arte tecnológica. 
No campo do desenvolvimento tecnológico, só é permitida uma aceitação cega. É essa imposição que ele deseja recusar (Armitage, Virilio, 2000).

Para nós, a recusa do autor em aderir ao culto tecnológico de nosso tempo é resultado de seus desenvolvimentos intelectuais anteriores, bem como de suas experiências de vida. Em suas vivências no campo de batalha da Segunda Guerra Mundial, Virilio enxergou um ponto de ruptura marcado pela verticalização do conflito, pressagiando a globalização ou globalitarismo que ele irá denunciar posteriormente (Armitage, Virilio, 2000; Virilio, 1994, 1996, 1999); a guerra se torna o palco para um extraordinário desenvolvimento tecnológico, que seria prolongado no período da Guerra Fria com a corrida armamentista e espacial. Em suas análises, esse novo tempo é regido pela dissuasão nuclear, que leva à hipertrofia dos Estados, pautados, cada vez mais, por interesses militares.

Sua modalidade peculiar de catolicismo o direciona então à antiestadolatria, e permite a elaboração de uma crítica ácida do cristianismo que se alia aos interesses militares - tornados interesses gerais do Estado. Virilio produz tais análises por meio de uma visão intersticial que guarda relações com seus movimentos no campo da arte. E, nesse terreno, em conjunto com as incursões na arquitetura, ele observa como somos diariamente adestrados, em nossos perceptos e afetos, por um sistema cultural que exclui as diferenças, nega a corporeidade e nos torna reféns de uma crescente militarização.

\section{Considerações finais}

Tendo em vista o objetivo central do artigo - relembrar o ensaísta francês Paul Virilio como autor-chave para entender os tempos atuais -, procuramos caminhar nos interstícios dos enquadramentos biográficos e de marcos conceituais, como formas de construção de um pano de fundo para a apresentação de alguns entendimentos centrais em sua obra. A partir daí, encontramos cinco eixos em torno dos quais buscamos pensar a contribuição de Virilio: primeiramente, as experiências da infância e da adolescência do autor em meio à ocupação nazista durante a Segunda Guerra Mundial. Para o próprio Virilio, essa vivência foi a principal influência de seu trabalho. Depois, o interesse do autor pelo campo da arte, desde sua formação na École de Métiers d'Art, em Paris, até suas experiências com as antiformas, que resultaram em algumas ideias centrais para seu trabalho intelectual posterior. Também sua incursão no campo da arquitetura e do urbanismo, a partir da participação no grupo Architecture Principe, 
de onde advêm importantes obras e conceitos. Observamos ainda a conversão de Virilio ao catolicismo no movimento dos padres-operários na França e a maneira como essa passagem impactou sua visão política. Por último, exploramos brevemente sua formação intelectual com Merleau-Ponty na Sorbonne, bem como seu posicionamento como crítico da arte tecnológica.

Entretanto, como observado na introdução deste texto, seria errado encerrar a interpretação da obra de Paul Virilio em qualquer um desses interstícios. De fato, este texto constitui apenas uma contribuição a pesquisas que devem prosseguir no caminho traçado por outras tantas questões: como se estrutura o pensamento de Virilio? Quais são seus principais conceitos? Quais são as contribuições de seu pensamento para o estudo do fenômeno comunicacional? Nesse sentido, entendemos ser necessário retornar à obra do autor e à sua reconstrução da história das novas velocidades, com o surgimento dos motores que nos conduzem, na contemporaneidade, a uma sociedade inteiramente atravessada pelas tecnologias de informação e comunicação. Para isso, devemos investigar de maneira minuciosa a dialética proposta por Virilio, que estabelece a dinâmica das ultrapassagens em busca do poder, que termina por produzir mutações profundas nos modos como percebemos, pensamos e organizamos o mundo. Assim, torna-se igualmente necessário realizar uma perquirição profunda de conceitos como dromologia, dromoscopia e dromocracia (ideias desenvolvidas ao longo de todas as obras do autor), pois neles se ancora uma nova via de compreensão dos fenômenos do mundo, incluindo o fenômeno comunicacional. Entendemos que Virilio se torna um autor fundamental para nossos dias e, com esta breve contribuição, esperamos observar o surgimento de ainda mais leitores dispostos a discutir as ideias do autor. Podemos ressoar as ideias de Derian (1998, p. 12) e dizer que este artigo buscou "usar a vivacidade do pensamento do autor para dar um sopro de vida a alguns sujeitos moribundos da modernidade tardia e das altas tecnologias". Devemos prosseguir nesse caminho.

\section{Referências bibliográficas}

ARMITAGE, John (ed.). Paul Virilio: From Modernism to Hypermodernism and Beyond. Londres: Sage, 2000.

. Virilio Live: Selected Interviews. Londres: Sage, 2001.

ARMITAGE, John; VIRILIO, Paul. "From Modernism to Hypermodernism and Beyond: An Interview with Paul Virilio". In: ARMITAGE, John (ed.). Paul Virilio: From Modernism to Hypermodernism and Beyond. Londres: Sage, 2000, p. 25-56. 
CARLUT, Christiane; JOUBERT, Dominique; VIRILIO, Paul. "Paul Virilio". In: ARMITAGE, John (ed.). Virilio Live: Selected Interviews. Londres: Sage, 2001, p. 121-127.

DERIAN, James der. The Virilio Reader. Malden, Oxford: Blackwell, 1998.

JAMES, Ian. Paul Virilio. New York: Routledge, 2007.

LIMON, Enrique; VIRILIO, Paul. "Paul Virilio and the Oblique”. In: ARMITAGE, John (ed.). Virilio Live: Selected Interviews. Londres: Sage, 2001, p. 51-57.

LOTRINGER, Sylvere; VIRILIO, Paul. Guerra pura: a militarização do cotidiano. São Paulo: Brasiliense, 1984.

REDHEAD, Steve. Paul Virilio: Theorist for an Accelerated Culture. Toronto: University of Toronto, 2004.

SANTOS, Laymert Garcia. “Apresentação”. In: LOTRINGER, Sylvere; VIRILIO, Paul. Guerra pura: a militarização do cotidiano. São Paulo: Brasiliense, 1984, p. 7-12.

VIRILIO, Paul. Negative Horizon: An Essay in Dromoscopy. Londres: Continuum, 2005. . La inseguridad del territorio. Buenos Aires: La Marca, 1999.

. Velocidade e política. São Paulo: Estação Liberdade, 1996.

. Bunker Archeology. New York: Princeton Architectural Press, 1994. 